\title{
EVOLUTION OF THE STEEL LADLE REFRACTORIES LINING IN LAST DECADE*
}

\begin{abstract}
Increased worldwide highly competition in steel market imposes innovative measure for the steelmaker targeting cost reduction and climate-friendly steelmaking process in order to have the ability to withstand the pressure of the market. At the same time the demand for high purity and highest quality steels continues to grow from year to year, especially in the sector automotive in transportation of oil and gas, in the construction Industry and in the manufacture of heavy plate. As they allow producers to be up to the requirements while allowing expanding their product mix, new secondary metallurgical treatments have become a must additionally to standard equipment elements of steel plants modern. Most of these treatments occurs in the steel ladle increasing the pressure to ensure a reliable and as possible neutral reactor. Intelligent solutions for refractory lining ladles should integrate better adaptation to the operational process parameters and the high reliability/availability at the best cost/performance. This challenge has conducted Refratechnik to develop new concepts to overcome the frontier between shaped and unshaped materials and that's what will be covered in this paper
\end{abstract}

Keywords: Steelmaking; Steel ladle; Refractories; Intelligent concepts.

1 Dr.rer.nat,\& Dipl. Eng. Mineralogy; Tech.\& Mark. Man. Refratechnik Steel GmbH, Düsseldorf, Germany.

2 Business Economist; Technical Sales Manager; Refratechnik Steel GmbH; Düsseldorf, Germany.

3 Dr, Eng. Research \& Development Manager, Refratechnik Steel GmbH, Düsseldorf, Germany.

4 Metalurgical Eng.; Technical \& Com. Manager; MACER Brasil Ltda; Mogi das Cruzes-SP Brasil. 


\section{INTRODUCTION}

The steel ladle is playing in the modern steelmaking an absolutely critically role as this is the place for:

- transferring the liquid metal (the original function)

- homogenizing the steel temperature

- allowing complicate metallurgical treatments like CAS-OB, $\mathrm{RH}-\mathrm{OB}, \mathrm{VTD}$, etc...

- being part of the treatment by enabling the flotation of the inclusions

- minimizing thermal losses vs time

- maximizing the level of safety and avoiding break out

But increased worldwide globalization in term of economy and competition imposes innovative measure for the steelmaker targeting cost reduction in order to have the ability to withstand the pressure of the market but also considering the tightening global $\mathrm{CO} 2$ and NOx emission requirements, which results in higher energy prices.

Because of the very wide reange of processing conditionos encounteered in the ladle their is considerable variation in safety construction for preventing a steel breakout. In case of a failure in the working lining the permanent lining must be sufficient to allow finishing the process of the engaged charge.

\section{INSULATION AND SAFETY LINING}

\subsection{Insulation}

The mode of insulation is critical for the ladle as this can influence strongly the other refractory costs. It can be considered in European steelshop that the necessary elevation of the temperature of $1^{\circ} \mathrm{C}$ induces an over cost of $50 € / t$ in the total processing (EAF or BOF). The right insulation is also avoiding too much temperature stratification in the ladle.

Key criteria to respect for a good insulation:

- The finest as possible as the main function of the ladle is to maximize the capacity in the majority of the case. The refractory costs are completely negligible considering an extension of volume of just $1 \mathrm{~cm}$ in the diameter.

- The more insulating efficient over the full campaign of the ladle. A lot of highly insulating solution are very shortly effective. Main reason is sometimes the compaction of this layer due to the cycle of movement of the ladle, but also over
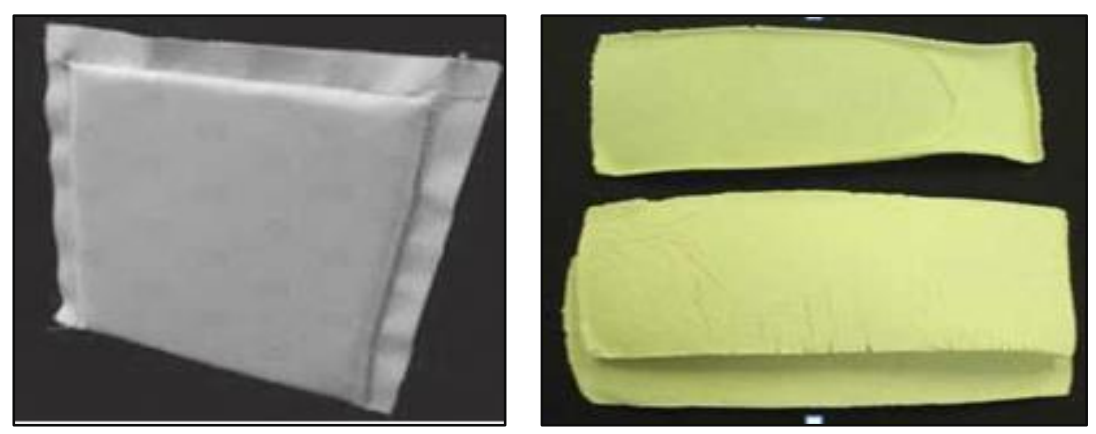

Fig. 1 Modification of a porous board at $1050^{\circ} \mathrm{C}-5$ hours

temperature at the hot face. It is extremely important to consider the worst case 
of the working lining at the end of the campaign for designing the safety and insulation lining. In particular the top insulating microporous boards are limited to a max process temperature close to $1000-1100^{\circ} \mathrm{C}$ and collapsing very quickly if the temperature rise up (fig.1)

- Generally the solution we are proposing are considering twin layer allowing to respect the same heat transfer during the full campaign of the ladle (Fig.2):

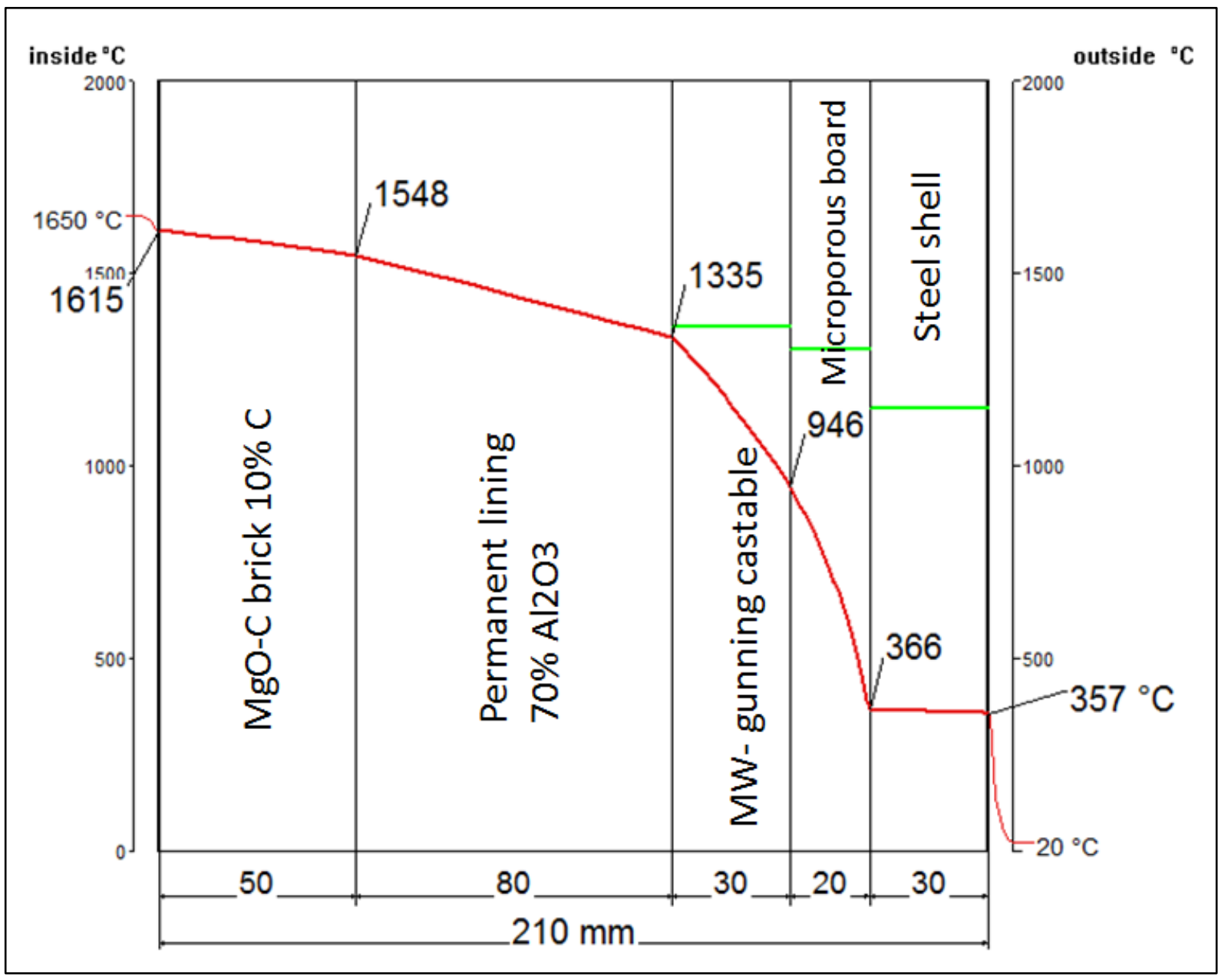

Fig.2: typical insulation concept integrating the residual thickness of the working lining

\subsection{Permanent/ Safety lining}

The concept of the permanent lining is dependent of the local configuration (labour cost), availability of the ladle, and type of working lining.

Because of the needed diversity, un-shaped refractory products can be a serious alternative option whenever the brickwork creates problems here.

- Side wall safety lining concept:

For example a burnt MgO brick for aluminium killed steel or high alumina or silicon killed steel is the most suitable solution for the slag area back lining in terms of chemical composition and resistance against attack of basic slag. However, $\mathrm{MgO}$ bricks may be loosened after breaking out the wear lining, when the ladle is tilted in 
the ladle stand. Entire lining layers may fall off, creating additional cost and longer downtime.

A monolithic lining is installed without joints, secured depending of the design by anchors or steel fibres.

Today, monolithic solutions for permanent lining castable are still based on alumina raw materials. To meet the requirements of a basic slag environment reliably, Refratechnik has developed several castable for steel ladle permanent lining with different raw material and binding systems.

For monolithic application in steel ladles, usually a mould construction consisting of steel plate sections is used. For easy demoulding a retractable formwork is suitable (fig.3).

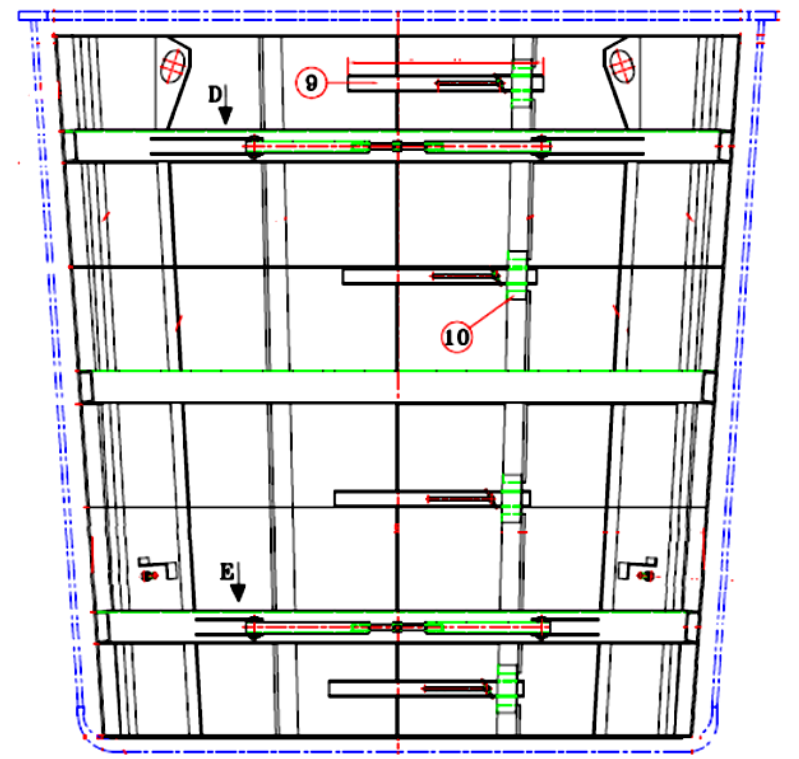

Fig.3: Retractable mould for casting the safety

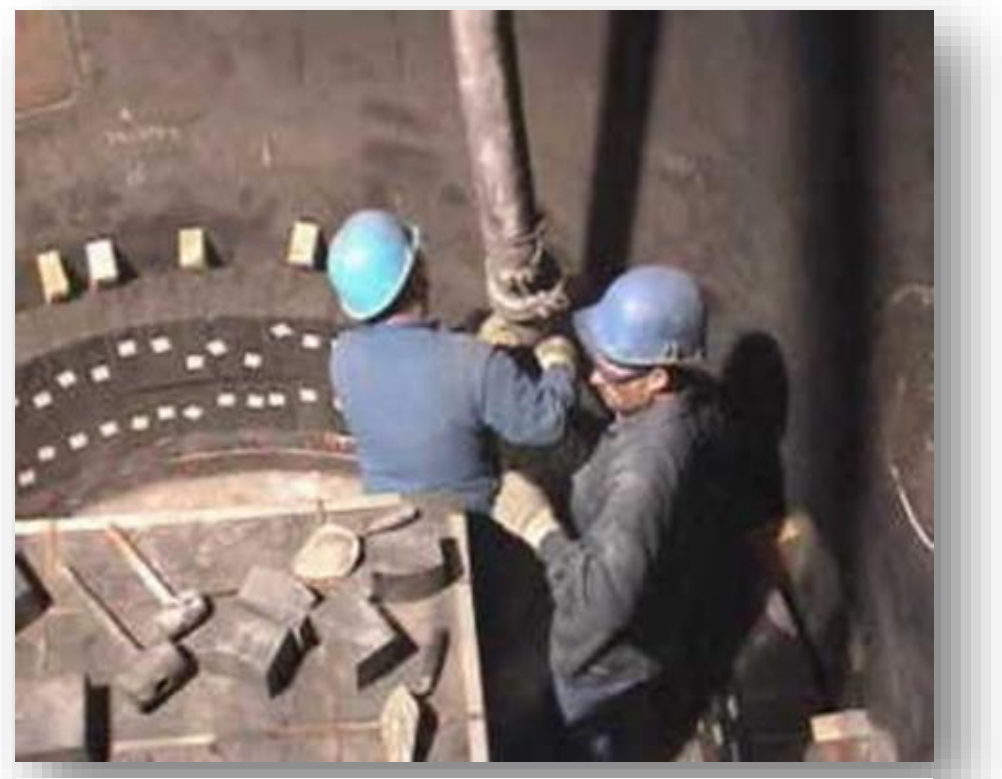

Fig.4: Casting behind the bricks

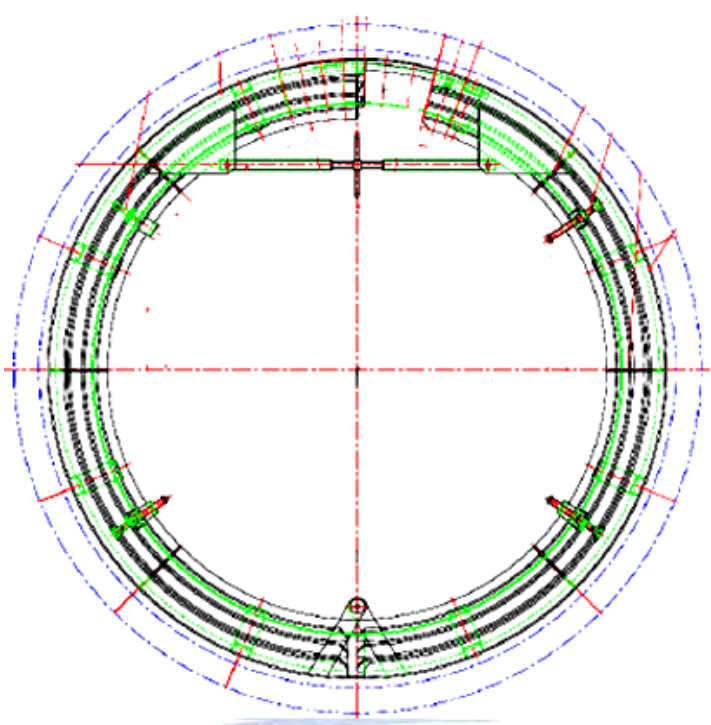

Meanwhile the set-up of the mould is expensive, timeconsuming and often not easy (could take 1 shift for the positioning in case of strong deformed ladle and thin permanent lining), as the shape of the ladles may vary due to thermal deformation or other effects.

REFRATECHNIK
recommends considering
the alternative use of the
ladle's wear lining as the
inner moulding (see details
in Fig. 8). After bricking up
the wear lining, leaving a
specified space between


bricks and steel shell or insulation, the self-flowing castable will be poured into the gap behind the bricks (Fig.4 ). Vibration is not required; heating of the completed ladle is easy.

Other possible solution the shotcreting:

Another way for avoiding using a formwork is the shotcreting. Our range for this application is based on sol/gel product up to cement containing castable.

- Bottom safety lining concept:

Both possibilities are still available with traditional shaped or unshaped material. The unshaped solution is allowing more fantasy in the design in particular for proposing an inclined bottom that is maximizing the yield. Our experience is shown than depending of the ladle size customer can save more than 1 ton of steel per heat!

Precast shapes are advantageous for time installation savings Here also it is possible for smaller ladle to use a full bottom or segment type.

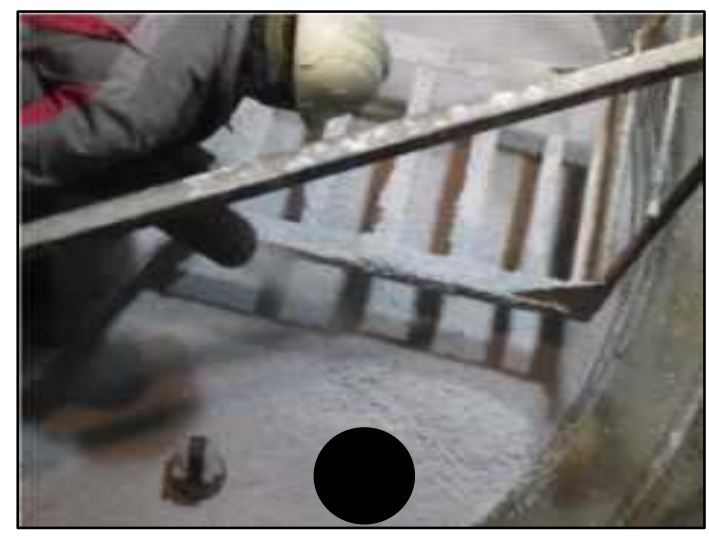

Fig.5. A: casting on site the bottom $B$ : Using precast segments for the safety lining

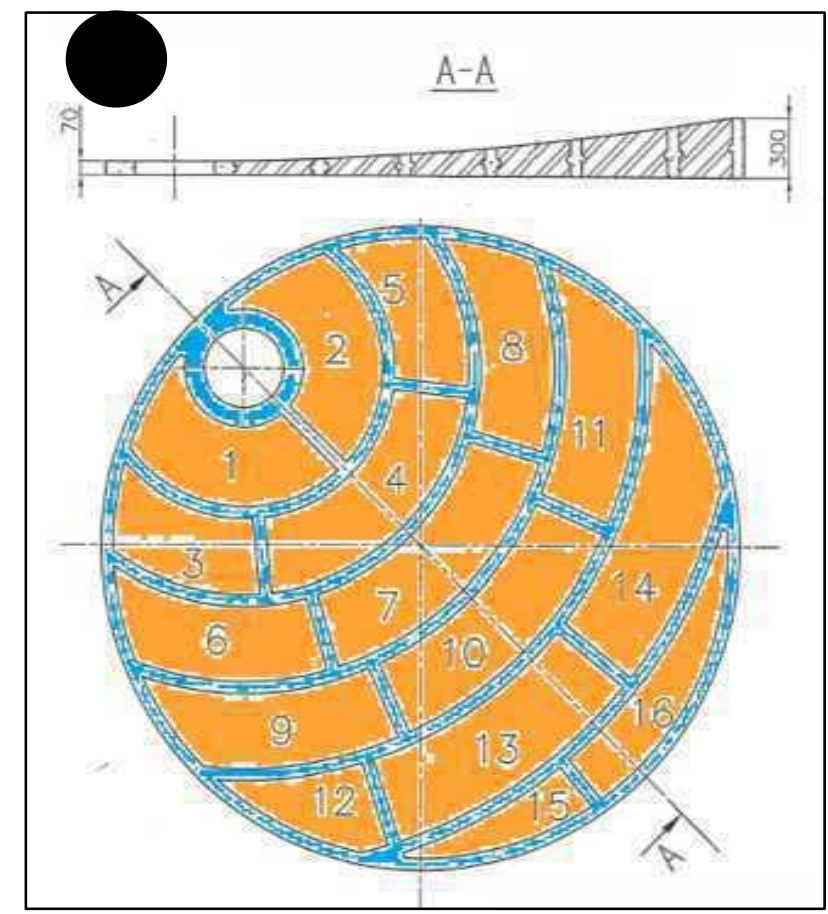

\section{WORKING LINING}

3 main zones have to be considered in a $1^{\text {st }}$ approach:

- Slag line

- Barrel

- Bottom

Share between oxygen and electrical steel making depending on maturity of steel market (availability of scrap) in a region:

- Americas, Europe, Japan 40-50\% EAF

- China $<10 \%$ EAF

- India 60\% EAF; limited scrap but HBI/DRI instead 


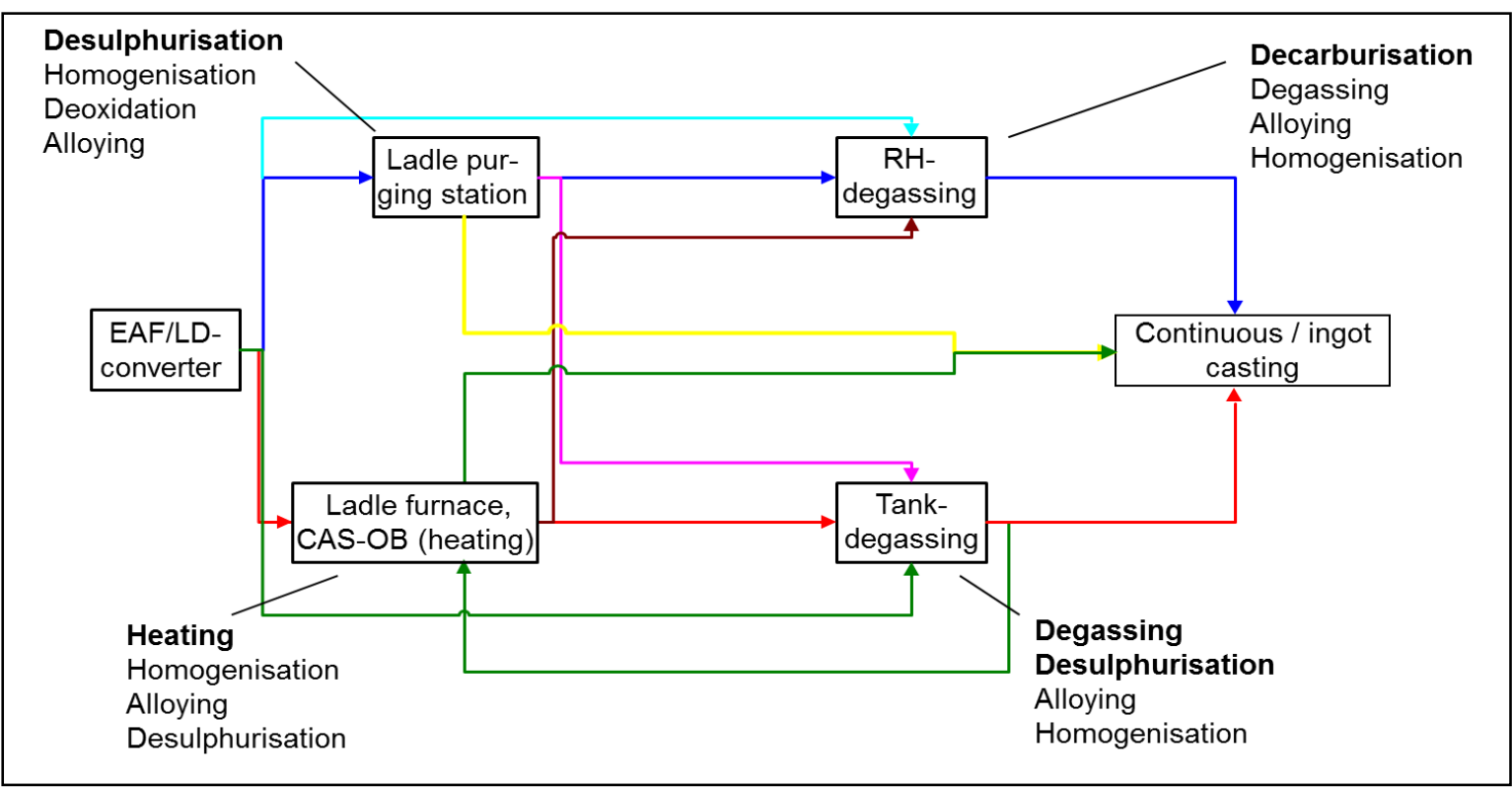

Fig.6. Flexibility of the process routes

The manufacturing route is determining strongly the type of working lining[1]. In particular the de-oxidation practice is critical. Various processing are currently used:

- Silicon or more exactly (ferrosilicon): traditional for long products (more economical than aluminium) and for small final product dimension (wire) with high cleanliness restrictions less problematic than aluminium; systematically used for stainless steel due to chemical affinity to chrome

- Aluminium (most affinity to oxygen $\Rightarrow$ most efficient), standard for flat products

- Dual killed steel $(\mathrm{Al}+\mathrm{Si})$

- Manganese

The slag chemistry is strongly impacted by this operation (Table 2)

\begin{tabular}{|l|l|l|l|l|l|l|l|l|}
\hline $\begin{array}{l}\text { Killing } \\
\text { type }\end{array}$ & $\mathrm{TiO}_{2}$ & $\mathrm{FeO}$ & $\mathrm{CaO}$ & $\mathrm{SiO}_{2}$ & $\mathrm{Al}_{2} \mathrm{O}_{3}$ & $\mathrm{MnO}$ & $\mathrm{Mg0}$ & $\mathrm{P}_{2} \mathrm{O}_{5}$ \\
\hline Al killed & - & 3.74 & 57.16 & 11.26 & 21.71 & 1.79 & 4.25 & - \\
\hline Si killed & 1.18 & 2.54 & 44.45 & 26.13 & 5.48 & 3.05 & 17.8 & 0.73 \\
\hline
\end{tabular}

Table 2: Comparison of slag chemistry in Al- and Si- killed steel

Main criteria for the slag zone choice:

- For Al-killed steel, Mag-C bricks with anti-oxidant are suitable for a high corrosion and high abrasion resistance.

- For Si killed steel Mag-C bricks are working correctly. Alternatively in case of extremely lower basicity some alumina based castable (ULCC tabular-spinel basis) can show a good performance.

- Some steel shops are using both processing in same ladle. This is the worst case as no real satisfactory solution is possible and a compromise has to be chosen. Mag- $C$ still seems the best compromise in this case. 
Main criteria of choice for the metal zone:

- For Al-killed steel, Mag-C brick with low C content is widely used. Low C is preferable to have high abrasion resistance. Also helps to reduce the thermal conductivity of the brick.

- An AMC brick has also been used and has given encouraging performance. AMC bricks in lower metal zone are to be used depending on the slag residence time.

- For Si killed steel, Mag-C bricks are working well, but AMC bricks are not at all suitable. This is because the highly siliceous slags, the excess $\mathrm{SiO}_{2}$ cannot form $\mathrm{C}_{2} \mathrm{~S}$ with the available lime. With low basicity slag CMS forms, this means corrosion of refractory. (Same with $\mathrm{C}_{3} \mathrm{MS}_{2}$ )

- The Nascent SiO2 which immediately forms during killing is very active and attacks the $\mathrm{MgO}$ lining. If sufficient $\mathrm{CaO}$ is available, it can form $\mathrm{C}_{2} \mathrm{~S}$. Rather, resin bonded /pitch bonded dolomite product is most suitable for such area.

- Alternatively the monolithic solution is very effective in particular in the case of refilling at the end of the campaign (Fig. 7,8,9).

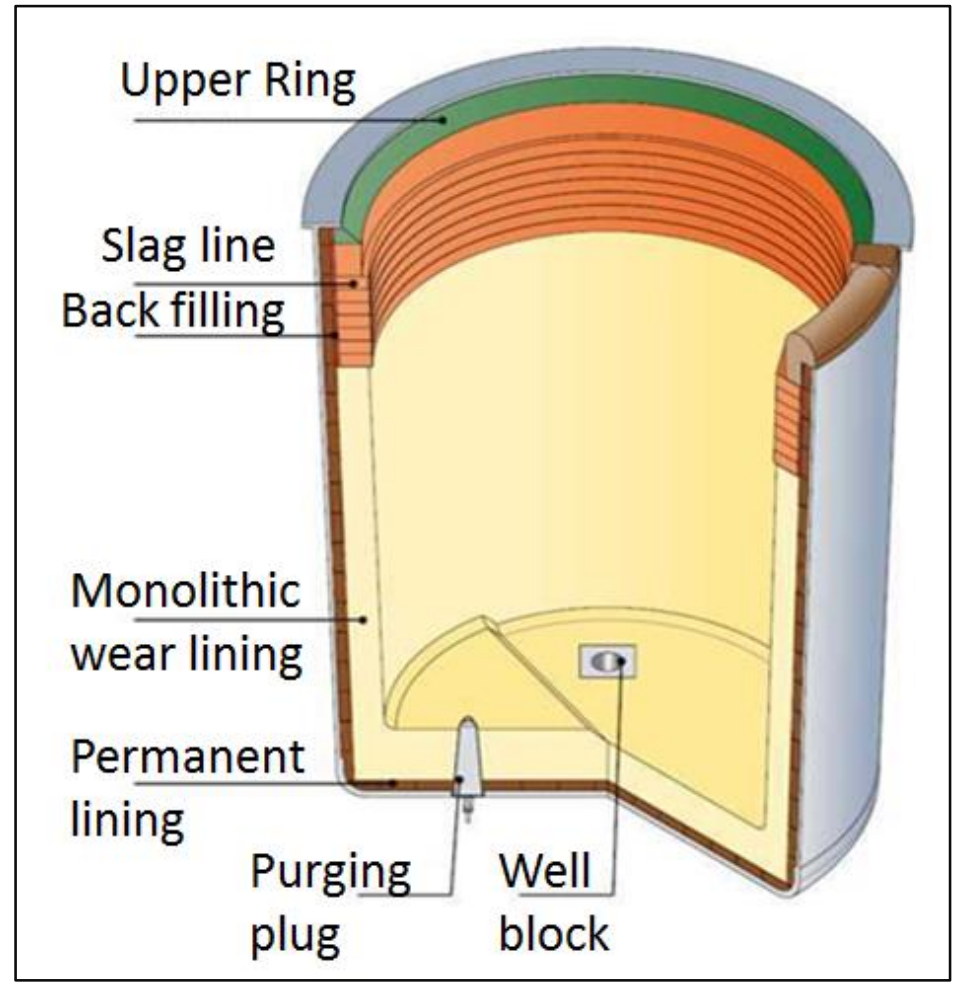

Fig.7: monolithic concept for the wall and bottom

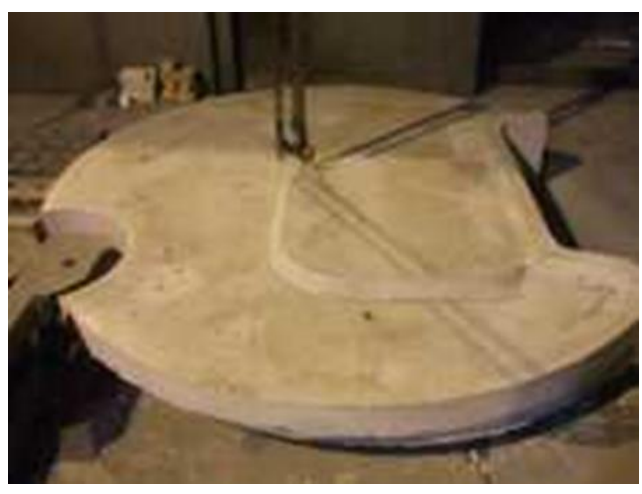

Fig.8: full precast monolithic bottom wear lining solution

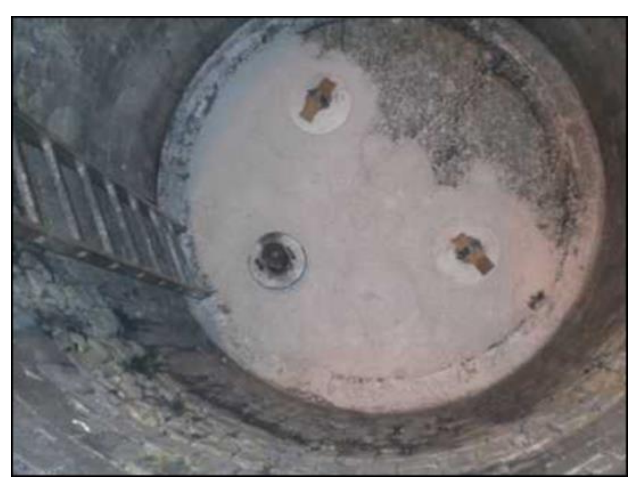

Fig.9: recasting of the bottom at the end of the campaign

\section{SOME RECENT INNOVATIONS}

Last decades have seen the development of the basic resin bonded Mag-C bricks due to their very good corrosion resistance to basic slag. Meanwhile some important deficit of these Mag-C bricks has been strongly limited concerning:

- Thermal shock resistance

- Higher thermal expansion

- Emission of fumes 


\subsection{Refraflex Binder}

Phenolic resin is the result of the condensation of phenol with formaldehyde (liquid, solid). Resulting is Carbon residue between 40-60\%. The standard temperature of processing is comprised between $20-50^{\circ} \mathrm{C}$. A duroplastic behaviour (does not soften) is the logical consequence (Fig.10).

REFRAFLEX Technology comprises a catalytically activation of the graphitisation of ordinary phenolic resins during coking (Fig.11). As a result the $\mathrm{C}$ - containing brick exhibits better thermo-mechanical properties

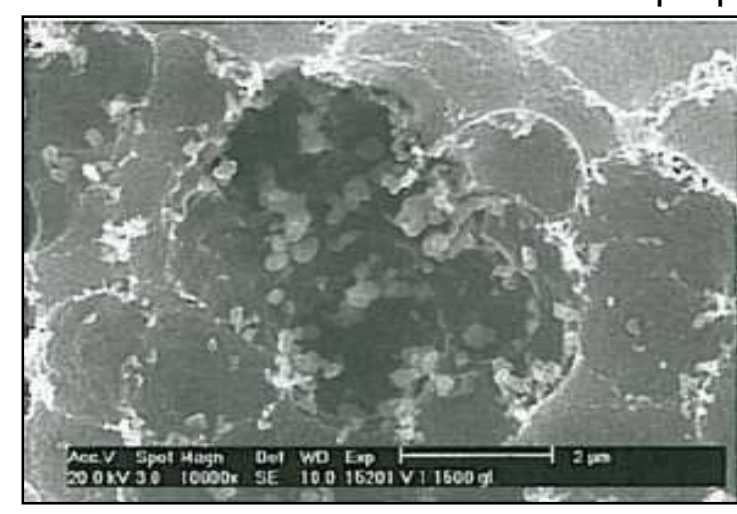

Fig.10: Resin without catalyst after coking at $1500^{\circ} \mathrm{C}$

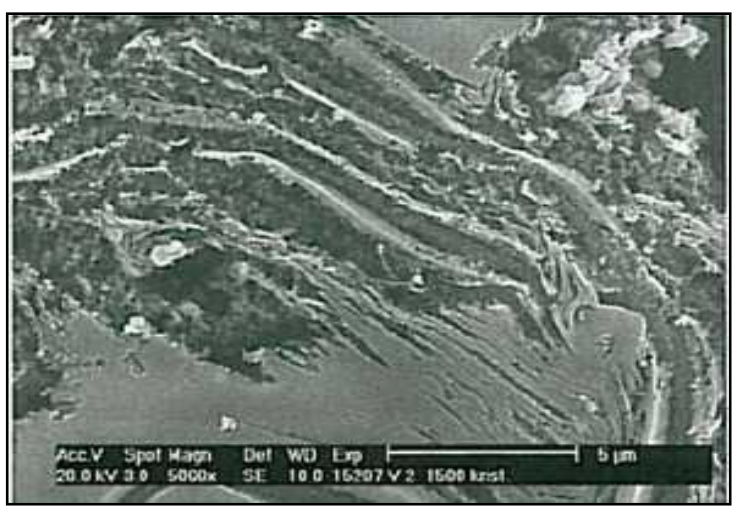

Fig.11: Catalytically activated resin after coking at $1500^{\circ} \mathrm{C}$

\subsection{Low Alpha brick concept}

The temperature during the ladle processing is varying a lot (Fig.12). Between phase end of tapping and end of treatment reversible expansion of the brick (Fig.13) can induce some damage in the lining.

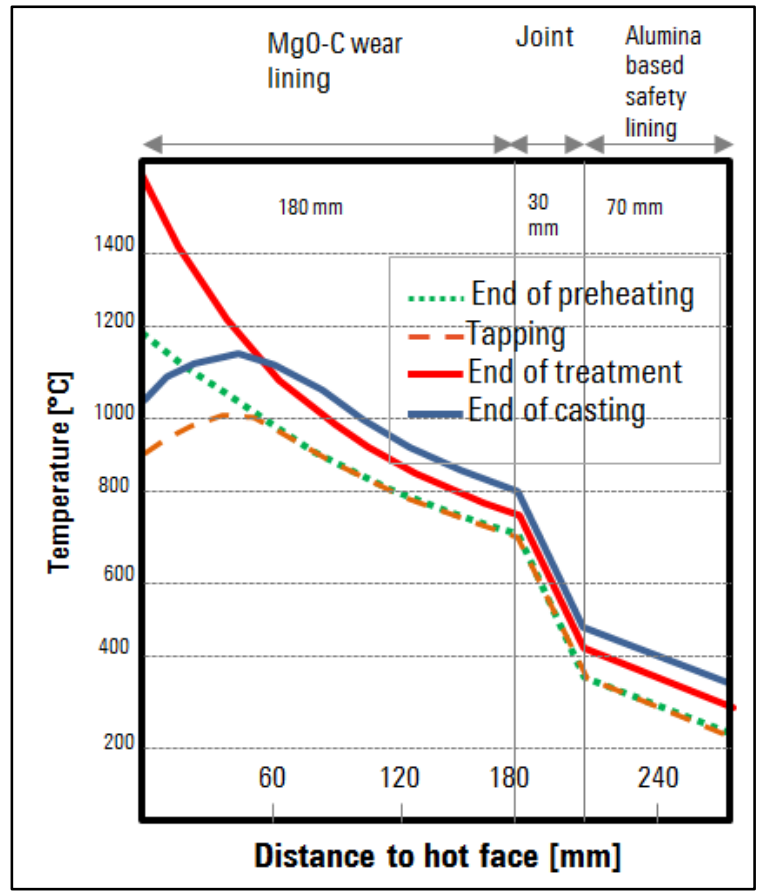

Fig.12. Temperature cycling during a ladle process

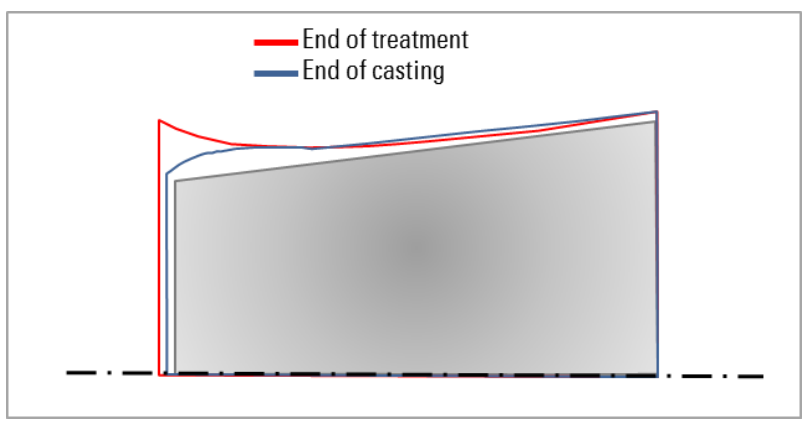

Fig.13: thermal expansion during ladle process (exaggerate scale)

This can have dramatic consequence for the lining as if using $\mathrm{P}$-shapes the bricks are layed in reclosed rings with a possible spalling issue and cobble formation (Fig 14). On the height this can also be very critical opening some cracks during intermediate phases with possible steel infiltration (Fig 15). 
Low-Alpha technology is strongly reducing the thermal expansion by $30 \%$ and the young modulus (50\%) while typical operational relevant properties are unaffected. The

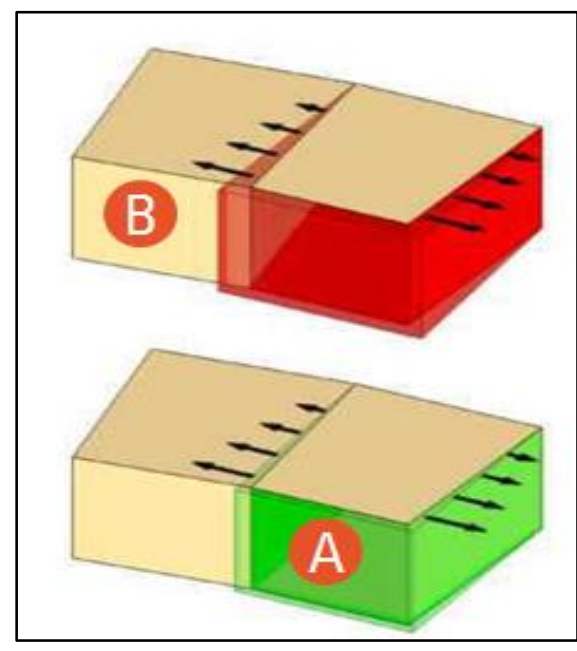

Fig.14: Radial expansion

A: Low Alpha MgO-C

B: Regular MgO-C

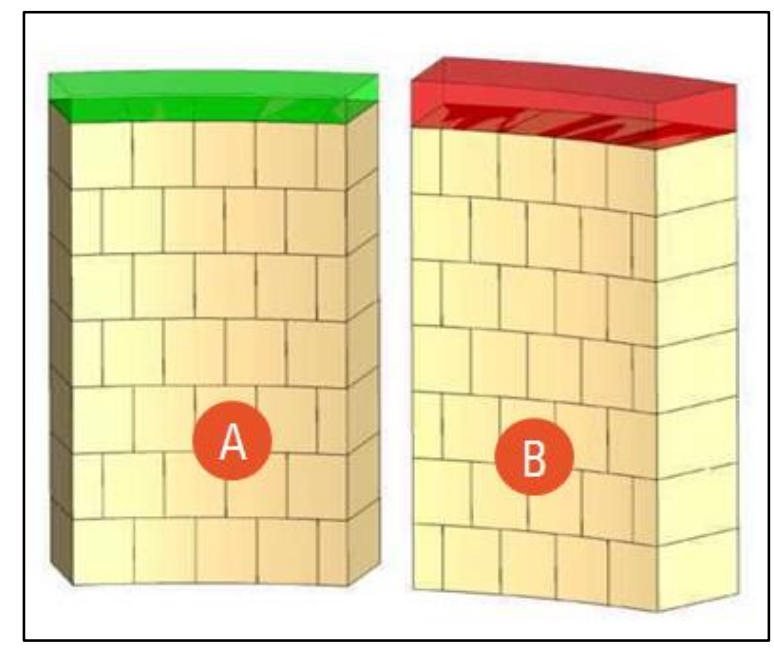

Fig.15: Vertical expansion

A: Low Alpha MgO-C

$\mathrm{B}$ : Regular $\mathrm{MgO}-\mathrm{C}$

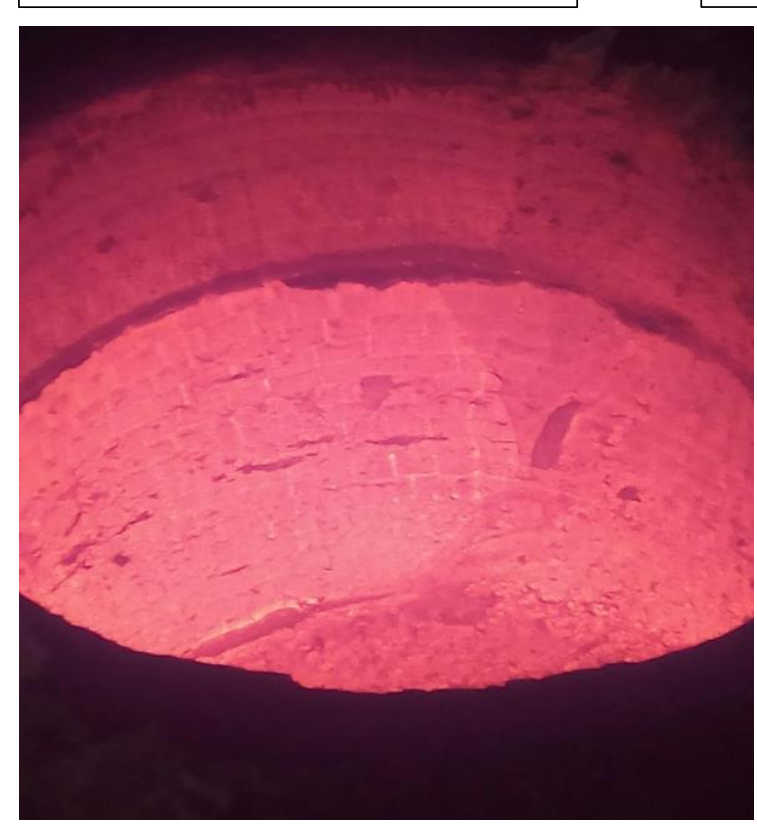

Fig. 16: Steel ladle in an Indian steel plant after more than 50 heats following consequence of Low-Alpha concept is no opening joints or deep cracks in the lining, depressed cobble stone formation, no infiltration between working and safety lining, improved thermomechanical properties.

Bricks with Low-Alpha Technology are highly suitable for:

- extremely alternating operative conditions with strong thermal cycling

- conditions with high thermomechanical loads

- $\quad$ complex and challenging conditions Industrial results show a potential up to $7 \%$ of the performance the Low-Alpha bricks.

This concept is now well experienced in Europe and India since more than 2 years.

\subsection{Ceramac brick concept}

Many steel shops are located in urban environment. All our brick do not contain nonhazardous component (free of polycyclic aromatic carbon hydrates) but the odor emissions during preheating of ladles with Mag- $\mathrm{C}$ bricks are sometimes disagreeable. The origin of emissions during heat-up procedure is the pyrolysis of artificial resin. All products of the CERAMAC $\AA$ family are pre-fired and as consequence:

- all pyrolysis products of binder resin have been removed from the brick

- no odor emissions during heat-up will take place

- emissions are reduced to a minimum 


\subsection{Micro-Zoning ${ }^{1}$}

New concept is not every time coupled with new products. Main zoning are sometimes limiting the cost/performance as for example some part of the wall are in over quality due to the choose of only one quality enabling a good resistance to local heavy wear (eccentric purging plug, lance,...). We are experienced in India and could decrease the cost ratio more than $17 \%$ just by introducing the right quality at the good place in regards with local logistic constrains.

\section{CONCLUSION}

Steel ladle is the most costly and sensitive tool of the steel shop. It is particularly important to optimize the lining for assuming the process complex functions in the secondary metallurgy. Beside the main role in the steel cleanliness, the refractory lining has to be safe avoiding all break-out as these incidences can be catastrophic on the operators and operative conditions.

Last feature concerns the cost that has to be considered in totality in a win/win manner with the supplier including all derivate (TCO-costing model) and not only in pure cost. This is the best way for progressing together.

\section{REFERENCES}

1 BUHR A.; VDEH steel ladle lining seminar, September 2014

2 TASSOT P., UJJWALL S., SCHEMMEL T.; New solution for the steel ladle cost approach; Unitecr'15, Wien 